\title{
The brazilian FRAX model: an introduction
}

\author{
D Cristiano A. F. Zerbini ${ }^{1}$ \\ Ben Hur Albergaria ${ }^{2}$ \\ 1. Paulista Center for Clinical Research - CEPIC - São Paulo - SP, Brasil \\ 2. Department of Social Medicine - Federal University of Espírito Santo, Vitória - \\ ES, Brasil and Osteoporosis Research and Diagnosis Center - CEDOES, Vitória - ES, Brasil
}

Osteoporosis is a systemic skeletal disease characterized by low bone mass and deterioration of bone microarchitecture leading to fractures secondary to minimal trauma. Vertebra, hip and forearm are common sites of these fragility fractures. The frequent association between fragility fractures and an increase in morbidity and mortality makes osteoporosis a huge socioeconomic and public health burden for many countries. This chronic bone disorder affects mainly postmenopausal women but can also develop in older man. It is calculated that at the age of 50 years, the lifetime fracture risk is $50 \%$ for women and $25 \%$ for men ${ }^{1}$.

Predictions based on epidemiological studies reveal a continuous increase in the world's population, probably reaching approximately 7.5 to 10.5 billion people by the year 2050. It is noteworthy that Latin America and the Caribbean region account for 9\% of this global population. Brazil, the biggest country in Latin American (LATAM), is the fifth most populous country in the world and accounts for $32 \%$ of the individuals in this region. The International Osteoporosis Foundation (IOF) published, in $2012^{2}$, a large epide- miological report - the Latin America Regional Audit - that gathered information from a literature search and/or provided by key opinion leaders on the burden of osteoporosis in 14 countries from Latin America. Firstly, this Audit showed that, although the current percentage of people 50 years of age and older lies between 13 and $29 \%$ in those countries, it is estimated that by 2050 these figures will be 28 to $49 \%$ with a $280 \%$ increase in the 70 and over population. The aging of these populations is a matter of concern due to the many diseases that mainly affect older people, including osteoporosis and its related fragility fractures. In LATAM, the current data on osteopenia and osteoporosis is scarce, but some studies bring good epidemiological information. Based on these, models for the FRAX calculation tool regarding the absolute risk for fragility fractures were constructed for 6 countries in LATAM: Argentine, Brazil, Chile, Colombia, Ecuador and Mexico.

FRAX $^{\circledR}$ is a computer-based algorithm developed by the Centre for Metabolic Bone Diseases, University of Sheffield Medical School, UK, first released in 2008 (http://www.shef.ac.uk/FRAX) ${ }^{3,4}$. The algo-

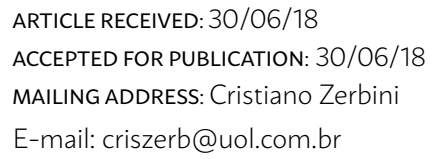


rithm, calculates the 10-year probability of a major fracture (hip, clinical spine, humerus, or wrist) and the 10-year probability of hip fracture in postmenopausal women and men aged 50 years or older.

Fracture risk is readily calculated from age, body mass index (BMI) and dichotomized (yes or no) clinical risk factors (CRFs) comprising prior fragility, parenteral history of hip fracture, current tobacco smoking, long-term oral glucocorticoid use, rheumatoid arthritis, other causes of secondary osteoporosis, and alcohol consumption. Rheumatoid arthritis and long-term use of glucocorticoids are risk factors independent of their action on BMD, the other secondary causes of osteoporosis considered in the algorithm are assumed to influence the increased risk for fracture by their lowering of BMD.

The bone mineral density (BMD) of the femoral neck can be optionally entered to enhance fracture risk prediction, but the FRAX algorithm output can be calculated without this information. If available, the inclusion of BMD in the calculation of fracture probability improves the accuracy of the assessment but it is most needed in individuals in whom fracture probabilities lie close to an intervention threshold. This is defined as the fracture probability at which physicians may intervene.

Fracture probability differs greatly in different parts of the world ${ }^{5}$, and the FRAX calibration has been made individually for each country where the epidemiology of hip fracture and death is published. The FRAX model is unique because unlike other algorithms, fracture probability is computed by taking the risk of fracture and the risk of death into account. The inclusion of risk of death is important because individuals with an immediate probability of death are less likely to suffer from fractures than those with longer life expectancy. In addition, some risk factors affect the risk of death as well as the risk of fracture. Examples include increasing age, low BMI, low BMD, long-term use of glucocorticoids, and smoking.

The association between risk factors and fracture risk has been constructed using information derived from large primary data of population-based cohorts from many countries around the world ${ }^{6,7,8}$. A series of meta-analyses based on those international cohorts identified clinical risk factors for fracture that provided independent information on fracture risk ${ }^{4}$. The relationship between risk factors for fracture included in the FRAX algorithm do not differ significantly among different countries and can be univer- sally used taking into account the available evidence.

FRAX models are currently available for 63 countries and 32 languages covering $79 \%$ of the world population aged 50 years or more. Ethnic-specific models are available only in the U.S. and Singapore. The FRAX model for Brazil has been internet launched in 2013 and the description of its construction with the calculation of the national incidence of hip fracture in Brazil became available in $2015^{9}$.

Brazil has a population of 207,690,929 inhabitants living mainly in urban areas. The country has 26 million people aged 60 years and older comprising $12.5 \%$ of the population, and this percentage will rise to 37.9 million in 2017. The country is divided into five regions, but the majority of the population lives in the Southeast $(42,13 \%)$, Northeast $(27.83 \%)$, and South (14.36\%). ${ }^{10}$

Data from four Brazilian epidemiologic studies (table below) were collected and analyzed to obtain national data on the incidence of hip fracture and mortality ${ }^{11-14}$. These studies have been conducted in the cities of Porto Alegre located in the South ${ }^{11}$, Marilia in the Southeast ${ }^{12}$ and Sobral and Fortaleza in the Northeast ${ }^{13,14}$ regions of the country.

The studies from Porto Alegre, Marilia, and Sobral were retrospective and the Fortaleza study was prospective.

The development and validation of the Brazilian FRAX model followed the method universally used for this tool ${ }^{3,4}$. The risk factors used in the Brazilian model were based on a systematic set of meta-analyses of worldwide population-based cohorts and validated in independent cohorts with over a million patient-years of follow-up (please see reference 9 for more information).

For the clinicians, FRAX provides a quantitative estimate for fracture risk and, thereby eliminates the

POPULATION AT RISK AND ANNUAL HIP FRACTURE RATES BY AGE AND SEX IN THE FOUR BRAZILIAN STUDIES

\begin{tabular}{|c|c|c|c|c|c|c|}
\hline \multirow[t]{2}{*}{ Age } & \multicolumn{2}{|c|}{ Fractures } & \multicolumn{2}{|c|}{ Population } & \multicolumn{2}{|c|}{$\begin{array}{l}\text { Incidence per } \\
100,000\end{array}$} \\
\hline & Men & Women & Men & Women & Men & Women \\
\hline $40-49$ & 14 & 10.5 & 68196 & 83471 & 21 & 13 \\
\hline 50-59 & 29.8 & 44.8 & 126376 & 160252 & 24 & 29 \\
\hline $60-69$ & 52.6 & 88.8 & 79423 & 111568 & 66 & 80 \\
\hline 70-79 & 47.6 & 223.2 & 34592 & 57286 & 138 & 390 \\
\hline $80-89$ & 21.2 & 113.9 & 3424 & 9020 & 618 & 1263 \\
\hline $90+$ & 3.4 & 21.5 & 297 & 953 & 1144 & 2252 \\
\hline
\end{tabular}


uncertainty of an individual's practitioner qualitative assessment of risk.

Regarding the intervention thresholds, the approach recommended by the National Osteoporosis Guideline Group (NOGG) in the UK ${ }^{15,16}$ was used in the Brazilian FRAX model. This methodology sets the intervention threshold at the age-specific fracture probability equivalent to women (or men) with a prior fragility fracture. Where access to BMD testing is limited, FRAX can be calculated using BMI and the use of BMD can be optimized by only testing those individuals in whom probabilities are close to the intervention threshold ${ }^{15,17,18}$. In this way, testing is confined to individuals at high (or low) risk with reasonable likelihood to be reclassified at low (or high) risk on the basis of the BMD test. Following this approach, two assessment thresholds were calculated and applied to the intervention threshold described above:

The threshold probability below which neither treatment nor a BMD test should be considered (lower assessment threshold).

The threshold probability above which treatment may be recommended without the need for BMD (upper assessment threshold).

The results of this calculation were displayed in figures showing the fracture probabilities equivalent to women (or men) with a previous fragility fracture in the FRAX Brazil model. These figures will be soon available for clinical use in the website of the Brazilian Medical Association.

FRAX represents a significant advance in the assessment of both women and men at risk of osteoporosis-related fractures and allows the tailoring of pharmacological interventions to high-risk subjects. However, it has limitations and must be used only as a guideline. The practitioner clinical judgment will, and should, supplant any calculated value. Furthermore, it is a tool in evolution, being refined as the databases are updated with more epidemiological information.

\section{REFERENCES}

1. Harvey N, Dennison E, Cooper C (2010) Osteoporosis: impact on health and economics. Nat Rev Rheumatol 6:99-105

2. Zanchetta j, Macdonald S (2012) The Latin America Regional Audit Epidemiology, costs \& burden of osteoporosis in 2012, Technical Report Edited by International Osteoporosis Foundation

3. Kanis |A, Johnell O, Oden A, Johansson H, McCloskey EV ,2008. FRAX and the assessment of fractur probability in men and women from UK. Osteoporosis Int 19:385-397.

4. Kanis JA, on behalf of the World Health Organization Scientific Group. 2008. Assessment of osteoporosis at the primary health-care level. Technical Report. WHO Collaborating Centre, University of Sheffield, UK. Available online at http://www.shef.ac.uk/FRAX.

5. Kanis JA, Johnell O, De Laet C, Jonsson B, Oden A, Oglesby A (2002) International variations in hip fracture probabilities: implications for risk assessment. J Bone Miner Res 17:1237-1244

6. Kanis IA, Oden A, Johnell O, et al. 2007. The use of clinical risk factors enhances the performance of BMD in the prediction of hip and osteoporotic fractures in men and women. Osteoporos Int 18: 1033 - 46.

7. Leslie WD, Lix LM, Johnansson H, Odén A, McCloskey EV, Kanis JA. 2010. Independent clinical validation of a Canadian FRAX tool: Fracture prediction and model calibration. J Bone Miner Res 25: 2350 - 8 .

8. Hippisley-Cox J, Coupland C. 2009. Predicting risk of osteoporotic fracture in men and women in England and Wales: Prospective derivation and validation of QFractures Scores. Br Med J 339: b4229.

9. Zerbini CAF, Szejnfeld VL, Abergaria BH, Johansson H, Harvey N, Kanis JA, McCloskey EV. Incidence of hip fracture in Brazil and the development of a FRAX model. Archives of Osteoporosis (2015) 10; 28

10. https://ww2.ibge.gov.br/home/estatistica/populacao/estimativa2017/default.shtm.

11. Castro da Rocha FA, Ribeiro AR. Low incidence of hip fractures in an equatorial area. Osteoporos Int 2003, 14 (6): 496-9.

12. Silveira VA, Medeiros MM, Coelho-Filho JM et al. Hip fracture incidence in an urban area in Northeast Brasil. Cad Saude Publica 2005, 21 (3): 907-12.

13. Komatsu RS, Ramos LR, Szejnfeld VL. Incidence of proximal femur fractures in Marilia, Brasil. J Nutr Health Aging 2004, 8 (5): 362-7.

14. Schwartz AV, Kelsey JL, Maggi S et al. International variation in the incidence of hip fractures: cross-national project on osteoporosis for the World Health Organization Program for Research on Aging. Osteoporos Int 1999, 9 (3): 242-53.

15. Kanis JA, McCloskey EV, Johansson $H$, Strom O, Borgstrom F, Oden A (2008) Case finding for the management of osteoporosis with FRAX--assessment and intervention thresholds for the UK. Osteoporos Int 19: 1395408.

16. Compston J, Cooper A, Cooper C, Francis R, Kanis JA, Marsh D et al (2009) Guidelines for the diagnosis and management of osteoporosis in postmenopausal women and men from the age of 50 years in the UK. Maturitas 62:105-108.

17. Johansson $H$, Oden $A$, Johnell $O$, Jonsson B, de Laet C, Oglesby A, et al (2004) Optimization of BMD measurements to identify high risk groups for treatment--a test analysis. J Bone Miner Res 19: 906-13.

18. Leslie WD, Majumdar SR, Lix LM, Johansson H, Oden A, McCloskey E, et al (2012) High fracture probability with FRAX usually indicates densitometric osteoporosis: implications for clinical practice. Osteoporos Int 23: 391-7. 